\title{
Interactive comment on "Biogeochemical diversity and hot moments of GHG emissions from shallow alkaline lakes in the Pantanal of Nhecolândia, Brazil” by Laurent Barbiero et al.
}

Anonymous Referee \#2

Received and published: 29 May 2017

This manuscript reports the water chemistry and greenhouse gases (GHG) emissions from lakes/ponds in the Pantanal region of Nhecolândia in Brazil. The authors found that although lakes were similar chemically (highly alkaline), they showed distinct biogeochemical functions. Black water lakes act as both $\mathrm{CO} 2$ and $\mathrm{CH} 4$ sources with low GHG emissions, while green water lakes are atmospheric $\mathrm{CO} 2$ sinks and $\mathrm{CH} 4$ source. The magnitude of the $\mathrm{CH} 4$ fluxes in the green water lakes depends on the presence and magnitude of the cyanobacterial blooms. The authors concluded that these lakes are active biogeochemically and may be subjected to hot moments of GHG emissions (i.e. during and after cyanobacterial blooms).

Printer-friendly version

Discussion paper

General comments 
It is now known that lakes and ponds are important contributors to the global carbon cycle. They receive process and emit large amounts of $\mathrm{CO} 2$ and $\mathrm{CH} 4$ at rates comparable with the land and oceans. This paper thus addresses an important question regarding the biogeochemical function of lakes in a particular area, whether they act as sinks or sources of carbon to the atmosphere. The study area is of great interests by the highly spatial heterogeneity and chemical diversity of the systems and the temporal dynamics governed by floods and droughts. In general, the paper is well written and clear. I, however, have concerns about the methodology, the sampling strategy and the data presentation, which could diminish the potential impact of the paper. I also have suggestions to improve the manuscript, which I think would allow the reader to better understand the results.

Although the study area seems of great interest on its own (proven by the several studies cited by the authors on the lakes description), I think that the authors spend too much effort on the area and general lakes description, especially regarding their chemistry. Although this is interesting, it is somehow disconnected to the GHG emissions and biogeochemistry function story. The authors made very little (if no) links between the lake chemistry and GHG emission/biogeochemical function. I suggest the authors to reduce significantly the description of the lake chemistry in the region, which I think other studies did properly. If the authors still feel that the chemistry should stay as an important part of the manuscript, they should reinforce the links that exist (statistically or conceptually) between water chemistry diversity and biogeochemical functions.

Linked to the previous comment that the authors emphasized on the chemical diversity of the lakes in the study area, choosing only 6 lakes might be not representative of this highly diverse/heterogeneous region. I acknowledge however that sampling many lakes is labor (and money) intensive, and that 6 lakes are better than none. I, however, suggest the authors to rework the manuscript to better reconcile and link the great diversity of lakes to the limited sampled lakes. What makes the authors think that these lakes are representative? It seems that they are representative chemically (if I

Printer-friendly version

Discussion paper
Interactive comment

\section{(1)}


understood right figure 2), but how are they biogeochemically? This should be clearer in the manuscript.

\section{Specific comments}

1) Lakes description:

While a thorough description of the sampled area (Pantanal lakes) was provided, the sampled lakes themselves were barely described. Basic information on lake depth, size, and thermal stratification is needed to properly interpret the chemical and biogeochemical results. Also, it is mentioned that the lakes are private and located on a farm. Are the catchments natural or managed? Forested or agriculture?

2) Data presentation:

The authors sampled the lakes during several seasons/periods (shown in Table 1) but only show $24 \mathrm{~h}$ cycle data. Figures 3 and 6 have no error bars, while Figures 7-10 show error bars. How these means and error bars are calculated? Also, Figure 1 shows 6 lakes, but Table 1 only 4 . This is very confusing for the reader. I thus strongly suggest adding a paragraph in the method section to properly describe the sampled lakes and the data used (and data not used), in which lakes, and the statistics made on the data. Also, all the figure captions should be more descriptive. For example, in Figure 3, the caption should mention what are the 4 panels, the different symbols, which day of the year it represents. . .etc.).

3) Chambers methodology: It is obvious to me that dragging chambers over the water induce artificial turbulence inside the chamber. The fluxes derived from this technique should overestimate real fluxes. The authors should provide further explanation of the potential impact of this bias on the interpretation of the results.

Printer-friendly version

4) In the green water lakes, the authors estimated annual $\mathrm{CH} 4$ flux of $8850 \mathrm{mmol} \mathrm{m}-2$ $\mathrm{yr}-1$, while CO2 influx was $1140 \mathrm{mmol} \mathrm{m}-2 \mathrm{yr}-1$. Even if all this CO2 consumption goes into biomass and that this biomass is completely used for methanogenesis, there is still 
about $7500 \mathrm{mmol}$ of $\mathrm{CH} 4$ that is missing and must be produced elsewhere. Where this methane comes from? Do the authors have ideas?

\section{Technical corrections}

P.4 L.26. I would use "shallow" instead of "low"

P11. L.16. C02 should be CO2

Interactive

comment

Interactive comment on Biogeosciences Discuss., doi:10.5194/bg-2017-108, 2017. 